\title{
F-Na (Fluorine-Sodium)
}

\section{H. Okamoto}

The partial Na-F phase diagram (0 to 50 at.\% F) in [Massalski2] was redrawn from [Moffatt]. Figure 1 shows the complete Na-F phase diagram for $P=10$ bar calculated by [2006Zha]. The isobar line for $P=1$ bar is shown with dotted lines. The phase boundary data used in the thermodynamic model were the same as those used in [Massalski2]. Therefore, the phase equilibria for condensed phases in Fig. 1 are in good agreement with [Massalski2].

\section{References}

2006Zha: S. Zhang, C. Brubaker, C. Jiang, M. Yang, Y. Zhong, Q. Han, and Z.K. Liu, A Combined FirstPrinciples Calculation and Thermodynamic Modeling of the F-K-Na System, Mater. Sci. Eng. A, 2006, 418, p $161-171$

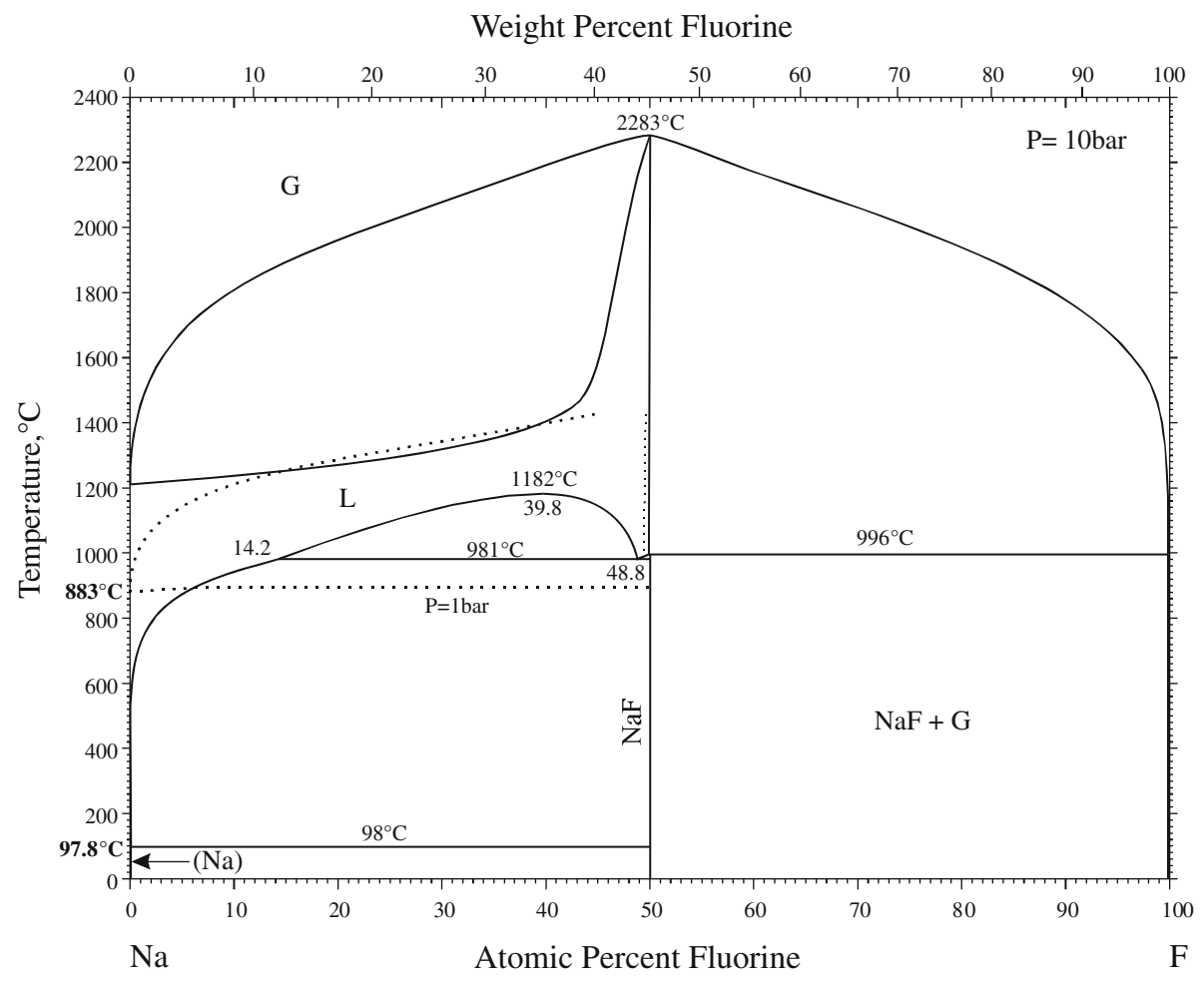

Fig. 1 Na-F phase diagram, from [2006Zha] 